\title{
BMJ Open Why are physical restraints still in use? A qualitative descriptive study from Chinese critical care clinicians' perspectives
}

\author{
Nianqi Cui (D) , ${ }^{1}$ Ruolin Qiu, ${ }^{2}$ Yuping Zhang, ${ }^{1}$ Dandan Chen, ${ }^{2}$ Hui Zhang, ${ }^{2}$ \\ Hongyu Rao, ${ }^{3}$ Jingfen Jin $^{1,4}$
}

To cite: Cui N, Qiu R, Zhang Y, et al. Why are physical restraints still in use? A qualitative descriptive study from Chinese critical care clinicians' perspectives. BMJ Open 2021;11:e055073. doi:10.1136/ bmjopen-2021-055073

- Prepublication history and additional supplemental materia for this paper are available online. To view these files, please visit the journal online (http://dx.doi.org/10.1136/ bmjopen-2021-055073)

Received 03 July 2021 Accepted 13 October 2021

Check for updates

(c) Author(s) (or their employer(s)) 2021. Re-use permitted under CC BY-NC. No commercial re-use. See rights and permissions. Published by BMJ.

${ }^{1}$ Department of Nursing, The Second Affiliated Hospital of Zhejiang University School of Medicine (SAHZU), Hangzhou, Zhejiang, China

${ }^{2}$ Faculty of Nursing, Zhejiang University School of Medicine, Hangzhou, Zhejiang, China ${ }^{3}$ Faculty of Nursing, Yunnan University of Business

Management, Kunming, Yunnan, China

${ }^{4}$ Changxing Branch Hospital, The Second Affiliated Hospital of Zhejiang University School of Medicine (SAHZU), Huzhou, Zhejiang, China

Correspondence to

Prof. Jingfen Jin;

zrjzkhl@zju.edu.cn

\section{ABSTRACT}

Objectives To understand why critical care clinicians still implement physical restraints, to prevent unplanned extubation and to explore the driving factors influencing the decision-making of physical restraints use.

Design A qualitative descriptive design was used. The data were collected through one-to-one, semistructured interviews and analysed through the framework of thematic analysis.

Participants and setting The study was conducted from December 2019 to May 2020 at one general intensive care unit (ICU) and one emergency ICU in a general tertiary hospital with 3200 beds in Hangzhou, China. The sampling strategy was combined maximum variation sampling and criterion sampling.

Results A total of 14 clinicians participated in the study. The reason why critical care clinicians implemented physical restraints to prevent unplanned extubation was that the tense healthcare climate was caused by family members' rejection of mismatched expectations. As unplanned extubation was highly likely to create medical disputes, hospitals placed excessive emphasis on unplanned extubation, which resulted in a lack of analysis of the cause of unplanned extubation and strict measures for dealing with unplanned extubation. The shortage of nursing human resources, unsuitable ward environments, intensivists' attitudes, timely extubation for intensivists, nurse experiences and the patient's possibility of unplanned extubation all contributed to the decisionmaking resulting in the use of physical restraints.

Conclusions Although nurses played a crucial role in the decision-making process of using physical restraints, changing the healthcare climate and the hospital management mode for unplanned extubation are fundamental measures to reduce physical restraints use.

\section{INTRODUCTION}

Annually, an estimated 13 million people are admitted to intensive care units (ICUs) worldwide $^{1}$ and evidence suggests that adverse events among critically ill patients are common. ${ }^{2}$ Unplanned extubation is recognised as the most common and potentially lifethreatening airway adverse event in the ICU and may cause adverse outcomes (eg, laryngeal bleeding, oedema, aspiration, hypotension, bronchospasm, arrhythmias and longer

\section{Strengths and limitations of this study}

This is the first study to explore the driving factors influencing the decision-making process of physical restraints use from a critical care clinicians' perspective.

- The sampling strategies of this study were combined maximum variation sampling and criterion sampling.

- Thematic saturation occurred only when both trained researchers reached a consensus.

- This study contained self-selection bias because all clinicians were from only one general tertiary hospital and clinicians who chose to participate may have had more interest in the use of physical restraints than did the clinicians who chose not to participate.

- This study did not explore the impact of the COVID-19 pandemic on critical care clinicians' clinical practice and clinical role, which may affect their decisionmaking regarding the use of physical restraints.

total duration of mechanical ventilation, ICU stay and hospital stay). ${ }^{3-5}$ Restraints including chemical restraints and physical restraints are most commonly used in the ICU to protect the patient from unplanned extubation. ${ }^{6}$ The definition of physical restraints is 'any action or procedure that prevents a person's free body movement to a position of choice and/ or normal access to his or her body by the use of any method, attached or adjacent to a person's body that he or she cannot control or remove easily'. ${ }^{7}$ However, there is no clear evidence of the utility of physical restraints in preventing unplanned extubation ${ }^{8}$ and their use increases many short-term and long-term physical and psychological adverse effects, such as neurological or cardiovascular injuries, delirium and posttraumatic stress disorder. $^{9}{ }^{10}$ Therefore, many policies and guidelines call for reducing the use of physical restraints, ${ }^{11}{ }^{12}$ but physical restraints still seem to be implemented frequently in some countries. A study conducted in 16 ICUs in China revealed that physical restraints were 
used in $59.07 \%$ of patients $;{ }^{13}$ Suliman ${ }^{14}$ reported that the prevalence of physical restraints use for patients in ICUs in Jordan was $35.8 \%$ and in Turkey, physical restraints were used on $85.6 \%$ of patients in the first 24 hours ${ }^{9}$. However, the rate of physical restraints use was $16.6 \%$ in the $\mathrm{USA}^{15}$ and physical restraints were only used in $8 \%$ of patients in 44 ICUs in Australia and New Zealand. ${ }^{16}$ Overall, there are cultural variations regarding the use of physical restraints worldwide and possibilities for the reduction of physical restraints.

Physical restraints minimisation as a global trend has been advocated by many studies. ${ }^{17}$ The implementation of physical restraints requires a medical order and research has shown that intensivists who are male and lack physical restraints knowledge prefer to order physical restraints. ${ }^{18}$ However, the actual clinical situation is that nurses apply physical restraints and seek a written prescription from the intensivist later. ${ }^{19}$ The literature suggests that critical care nurses are the primary decisionmakers of physical restraints implementation. ${ }^{20}$ Nurses' decision-making regarding the use of physical restraints is a complex trajectory and nurses' knowledge, attitudes and experiences about the use of physical restraints are essential factors that affect their decision-making. ${ }^{21}$ Due to the crucial role of nurses in the physical restraints minimisation process, nurse education activities are considered a necessary intervention to reduce the use of physical restraints because they could effectively improve critical care nurses' knowledge, attitudes and behaviour towards physical restraints. ${ }^{22}$ However, a Cochrane review found insufficient evidence supporting the effectiveness of educational interventions targeting nursing staff for preventing or reduction of physical restraints use. ${ }^{23}$ A study conducted in Turkey also found that although nurses' knowledge, attitudes and practices were at a very good level, physical restraints use was still widespread. ${ }^{24}$ The decision regarding physical restraints is influenced not only by perceptions but also by the knowledge and attitudes of nurses.

In our previous analysis,${ }^{25}$ we also found that critical care nurses knew the negative influence of physical restraints on patients, but they still commonly used physical restraints. The prevention of unplanned extubation seemed to be the driving reason behind physical restraints use. Why do critical care clinicians still implement physical restraints to prevent unplanned extubation? The objective of this study is to deepen our understanding of and explore the driving factors influencing the decisionmaking of physical restraints use from the perspective of critical care clinicians.

\section{METHODS}

\section{Design}

A qualitative descriptive design was used, ${ }^{26}$ adopting methods from Patton, ${ }^{27}$ which provided the framework for a sampling strategy involving purposeful sampling and data collection with semistructured interviews.
Qualitative descriptive studies tend to provide the most direct and essential answers to the concerns of practitioners and policy-makers. ${ }^{28}$ We applied the Standards for Reporting Qualitative Research as the guideline to ensure that the reporting of the study was transparent (online supplemental file 1$){ }^{29}$

\section{Setting}

The study was conducted from December 2019 to May 2020 at one general ICU and one emergency ICU in a general tertiary hospital with 3200 beds in Hangzhou, China. Most patients admitted to the general ICU were electively planned admissions and those admitted to the emergency ICU were unplanned admissions. The admission diagnoses of patients were mainly central nervous system disease, respiratory disease and trauma/burn and more than $75 \%$ of patients received mechanical ventilation. The family visitation policy was restricted visitation in both ICUs. The nurse-patient ratio was approximately $1: 2$ or $1: 3$ in both ICUs.

\section{Participants}

The sampling strategy was combined maximum variation sampling and criterion sampling. ${ }^{27}$ The inclusion criteria were registered nurses or intensivists at the study site; clinicians working in the general ICU or emergency ICU; clinicians with ICU experience (more than 1 year); clinicians with experience with physical restraints in the prior 3 months and clinicians with rotating work shifts. Participants who met the criteria were selected after considering the representativeness of factors such as gender, age, highest academic qualification, title and years of experience in ICUs. The criteria for exclusion were registered nurses or intensivists who declined to participate.

\section{Data collection}

Data collection was actually implemented from April to May 2020 since the original schedule beginning in February 2020 was delayed due to the impact of the COVID-19 pandemic. An interview guide (online supplemental file 2) was developed following the aims of this study and was reviewed by a postdoctoral-level qualitative researcher. The interview did not strictly follow the interview guide but followed the thoughts of the participants. The data were collected through one-to-one, semistructured interviews conducted by the first author who had experience with qualitative research. ${ }^{30-32}$ To avoid coercion in the sampling process, the first author was the only author involved in the recruitment process of participants and the rest of the team was not involved in the process. The first author is a $\mathrm{PhD}$ candidate and had not worked as a nurse at the study site and there had been no contact between him and these participants before. The first author wrote a letter clarifying the aim of this study and soliciting the cooperation of the participants. After obtaining verbal consent, the specific interview time and place were agreed on with the participant. As nurses played a crucial role in the decision-making process for 
physical restraints in the ICU, after reviewing the characteristics of all clinicians through the head nurse, the first author invited a critical care nurse who satisfied the criteria as the first potential participant because she had substantial clinical experience and might provide much information, followed by three critical care nurses, four intensivists and then six other critical care nurses. After obtaining written informed consent from the participants, the audio-recorded interviews, which were tagged with numbers and safely archived in files protected by passwords, officially started. The interviews took place in a quiet and private office outside the medical area and each interview lasted 50-70 min. Data collection and analysis were simultaneously conducted, which helped researchers identify thematic saturation. Thematic saturation occurred with the eighth nurse. To confirm thematic saturation, two additional critical care nurses were interviewed. However, these additional interviews did not bring out new themes.

\section{Data analysis}

The data were analysed in the framework of thematic anal$\mathrm{ysis}^{33}$ because themes related to the research questions can be constructed through an analysis of the data. Thematic analysis with an inductive approach was conducted by two researchers using Braun and Clarke's six-step framework: ${ }^{33}$ (1) become familiar with the data; (2) generate initial codes; (3) search for themes; (4) review the themes; (5) define and name the themes and (6) write up the final report. Data analysis began after the first participant interview. Transcription of the research materials was independently performed by the researchers and was cross-examined to ensure that the transcription contents were correct. An open coding process was used, so codes were not set but were developed and modified during the coding process. The two researchers jointly reviewed the themes they had independently extracted and exchanged opinions. After the data analysis of the first participant, the researchers reviewed the interview guide and found that there was no need for modification. The researchers

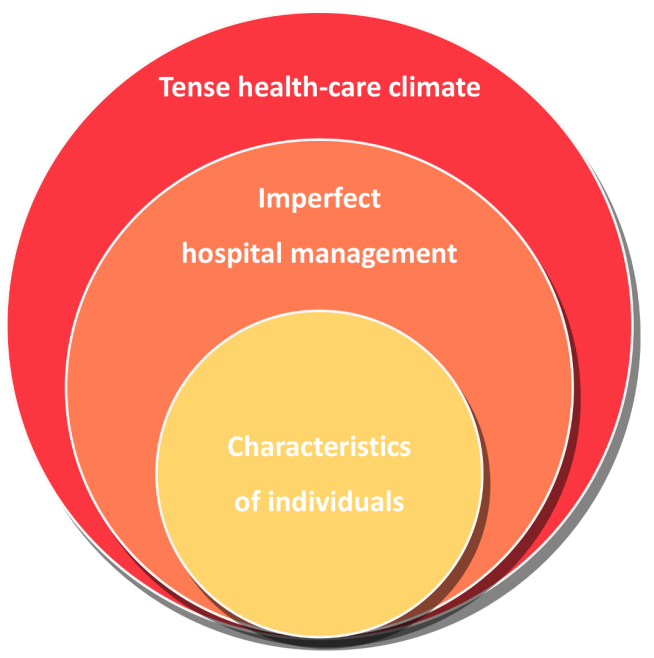

Figure 1 Themes and subthemes. conducted the process until the data collection and analysis were completed. The interview guide was not modified during the process. The ultimate theme was then determined by the authors through a consensus process.

\section{Patient and public involvement}

There was no patient and public involvement in the design, conduct or reporting of our research.

\section{FINDINGS}

A total of 14 clinicians participated in the study. Data analysis revealed 3 themes and 12 subthemes (figure 1). The participants' characteristics are shown in table 1 . Quotations from the transcripts were used to illustrate the theme and the subtheme.

\section{Theme 1: tense healthcare climate}

Participants reported that the tense healthcare climate forced them to use physical restraints to prevent unplanned extubation. The tense healthcare climate meant that the doctor-patient relationship was tense. Families of patients will not accept mismatched expectations and unplanned extubation is one such mismatched expectation. Once unplanned extubation occurs in patients, medical disputes might follow. Although flexible visitation seemed to help reduce physical restraints use, participants did not support this approach in tense healthcare climates.

Subtheme: families: the rejection of mismatched expectations Clinicians expressed that mismatched expectations were the discrepancy between the actual and expected outcome of patients. Family members did not allow unexpected outcomes in patients, which strained the doctorpatient relationship and the healthcare climate. This also made clinicians tend to be more conservative in the treatment of patients and only interested in avoiding making mistakes. Nurse 10 stated:

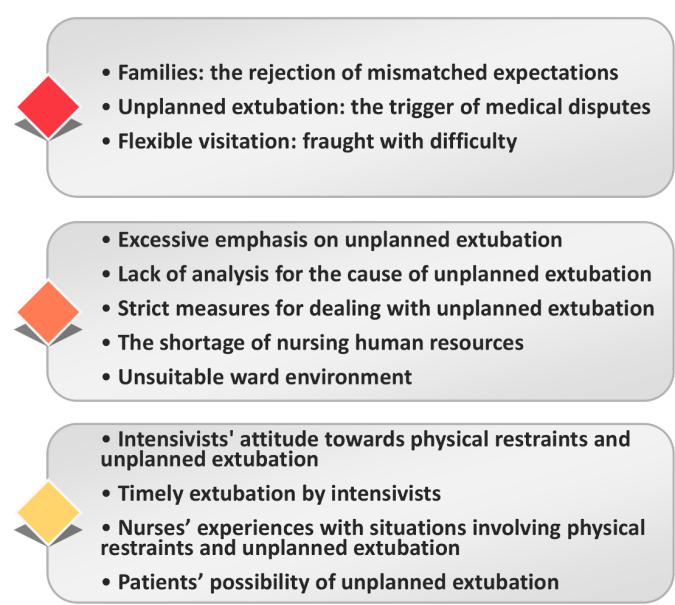




\begin{tabular}{lc} 
Table 1 Participants' characteristics & \\
\hline Characteristics & No. (n=14) \\
\hline Gender & \\
$\quad$ Male & 5 \\
Female & 9 \\
Age (years) & \\
$25-30$ & 5 \\
$31-35$ & 3 \\
$36-40$ & 4 \\
$>40$ & 2 \\
Median (range) & $35(29-54)$
\end{tabular}

Highest academic qualification

\begin{tabular}{|c|c|}
\hline Doctoral degree & 3 \\
\hline Master's degree & 3 \\
\hline Bachelor's degree & 8 \\
\hline \multicolumn{2}{|l|}{ Title } \\
\hline Senior title & 2 \\
\hline Intermediate title & 7 \\
\hline Junior title & 5 \\
\hline \multicolumn{2}{|c|}{$\begin{array}{l}\text { Years of experience in intensive care units } \\
\text { (ICUs) }\end{array}$} \\
\hline $1-5$ & 3 \\
\hline $6-10$ & 5 \\
\hline $11-15$ & 4 \\
\hline$>15$ & 2 \\
\hline Median (range) & $8(2-27)$ \\
\hline \multicolumn{2}{|l|}{ Position } \\
\hline Director & 1 \\
\hline Nurse team leader & 4 \\
\hline Attending physician & 3 \\
\hline Registered nurse & 6 \\
\hline \multicolumn{2}{|l|}{ Type of ICU } \\
\hline General & 8 \\
\hline Emergency & 6 \\
\hline
\end{tabular}

Patients' family members will not tolerate anything unplanned during treatment. This is a factor driving the contemporary doctor-patient relationship to come under a large degree of strain. This also affects doctors' attitudes towards their work, making them more conservative in their approach to treatment. The primary principle in their approach becomes, simply, do not make a mistake.

\section{Subtheme: unplanned extubation: the trigger of medical disputes}

Participants stated that because of the negative effect of unplanned extubation on patients, for family members, it was a mismatched expectation, which might lead to medical disputes. Due to the impact of medical disputes on normal work, clinicians were very afraid of medical disputes. As nurse 1 put it:

Unplanned extubation may threaten patients' lives. Therefore, from the perspective of patients' family members, unplanned extubation is an unexpected situation, and this is highly likely to create medical disputes. We truly dread these treatment disputes, as we may have to inspect and review all of the records, and we will need to be in constant communication with the patients' family members. This process can be an arduous ordeal.

\section{Subtheme: flexible visitation: fraught with difficulty}

Participants emphasised that patients who were accompanied by family members might not be restrained. Flexible visitation increased opportunities for family members to accompany patients. Because of the tense healthcare climate and lack of medical knowledge of family members, there are many difficulties implementing flexible visitation. Nurse 4 expressed:

The patients' family members' presence and accompaniment have a strong effect on patients with delirium. Patients who are with their families generally do not need to be restrained.

Nurse 9 commented,

During visitation by a patient's family members, we will rarely conduct procedures. However, if visitations are flexible, the patient's family members may see us conducting invasive procedures, such as a deep vein puncture, which will cause bleeding. Family members usually lack professional knowledge to understand why copious bleeding could occur, and as a result, the doctor-patient relationship becomes strained. Not only can situations such as this give rise to treatment disputes, but flexible visitations can also increase the hospital's level of infection risk while increasing our workload. We do not agree with flexible visitation policies for this reason.

Nurse 10 stated,

It is impossible not to make mistakes during clinical work. If flexible visitation is implemented, some of our mistakes may be seen by the patient's family members and may trigger medical disputes or even legal disputes.

\section{Theme 2: imperfect hospital management}

Participants indicated that hospital management is often problematic. Hospitals placed excessive emphasis on unplanned extubation but lacked analysis for the cause of unplanned extubation and the measures for dealing with unplanned extubation were very stringent. The shortage of nursing human resources and the unsuitable ward environment all forced them to implement physical restraints. 


\section{Subtheme: excessive emphasis on unplanned extubation}

In participants' opinions, hospital management paid too much attention to unplanned extubation, which led to ignoring unplanned extubation related indicators. The low incidences of unplanned extubation were at the cost of increasing the use of deep sedation and physical restraints. Intensivist 4 said:

The hospital's demand for the incidence of unplanned extubation is almost 'perfect'. If something is too perfect, there is no doubt, how can it be done so well? What did you sacrifice? If the incidence of unplanned extubation is zero, is it not because of deep sedation? Is it not because of the use of too much physical restraints? However, deep sedation and physical restraints are not of concern to hospitals. This shows that there are problems in hospital management.

\section{Subtheme: lack of analysis for the cause of unplanned extubation}

Participants said that unplanned extubation occurring in patients was an adverse event. The nurse was the primary person responsible for an unplanned extubation. Hospitals lacked analysis for the cause of unplanned extubation, which may lead nurses to take on responsibilities that did not belong to them. Intensivist 1 expressed:

We lack sufficient analysis of the causes of unplanned extubation. However, the status quo understanding is that when cases of unplanned extubation occur, they must be adverse events for which the nurse must assume responsibility. In fact, nurse are sometimes nurses not responsible for these adverse events. Nurses should not always be made to take the blame for every case of unplanned extubation.

\section{Subtheme: strict measures for dealing with unplanned extubation}

Participants reported that handling adverse events was very stringent in the hospital. Hospital management linked unplanned extubation with the professional development of nurses, which caused nurses to take all measures to reduce unplanned extubation for their professional development. Moreover, nurses needed to criticise themselves in front of healthcare team members in the department for their 'mistakes'. Nurse 4 said:

Although unplanned extubation does not affect salary, it may have an impact on professional development. Thus, we will do everything possible to prevent unplanned extubation. Our unit's requirement regarding unplanned extubation is that such cases must not occur more than twice annually. When unplanned extubation occurs, the nurse responsible must read a statement of self-criticism in front of the unit's entire staff. This places us under great psychological pressure.

\section{Subtheme: the shortage of nursing human resources}

Participants stated that the shortage of nursing human resources caused them to have no time for accurate decision-making. Compared with daytime nursing resources, night-time nursing human resources were more deficient. Nurse 6 stated:

The actual clinical situation is that you need to manage two to three critically ill patients in the day shift and three to five in the night shift. We truly do not have time to consider physical restraints.

\section{Subtheme: unsuitable ward environment}

Participants described that the ward environment of the ICU can easily cause patient agitation and delirium. The current situation of the ward environment was unsuitable, which increased the possibility of implementing of physical restraints. Nurse 3 reported:

There is no natural light in our ICU, which causes patients to not know day and night. Moreover, there are many types of equipment in our ICU, such as infusion pumps and respirators, which make noise. Such a ward environment easily causes delirium and agitation in patients, on whom I need to use physical restraints.

\section{Theme 3: characteristics of individuals}

Participants expressed that the characteristics of intensivists, critical care nurses and patients all affect the decision-making process of physical restraints, such as the attitudes of intensivists towards physical restraints and unplanned extubation, timely extubation by intensivists, nurses' experience and the possibility of unplanned extubation of patients.

\section{Subtheme: intensivists' attitude towards physical restraints and unplanned extubation}

Some intensivists clearly supported the use of physical restraints because they believed that physical restraints were beneficial for medical safety. Intensivists are more concerned about the changes in the patient's condition than the use of physical restraints. Unplanned extubation affects the changes in the patient's conditions. Intensivist 2 stated:

I support the use of physical restraints. Physical restraints are advantageous to medical safety.

However, some intensivists did not recommend the use of physical restraints. Intensivist 1 said:

I am not supportive of the implementation of physical restraints. I know many developed countries that do not allow the use of physical restraints.

Furthermore, nurses described that the intensivists were indifferent and careless about physical restraints. Due to the attitudes of intensivists towards physical restraints, 
Unplanned extubation occurred

No unplanned extubation occurred

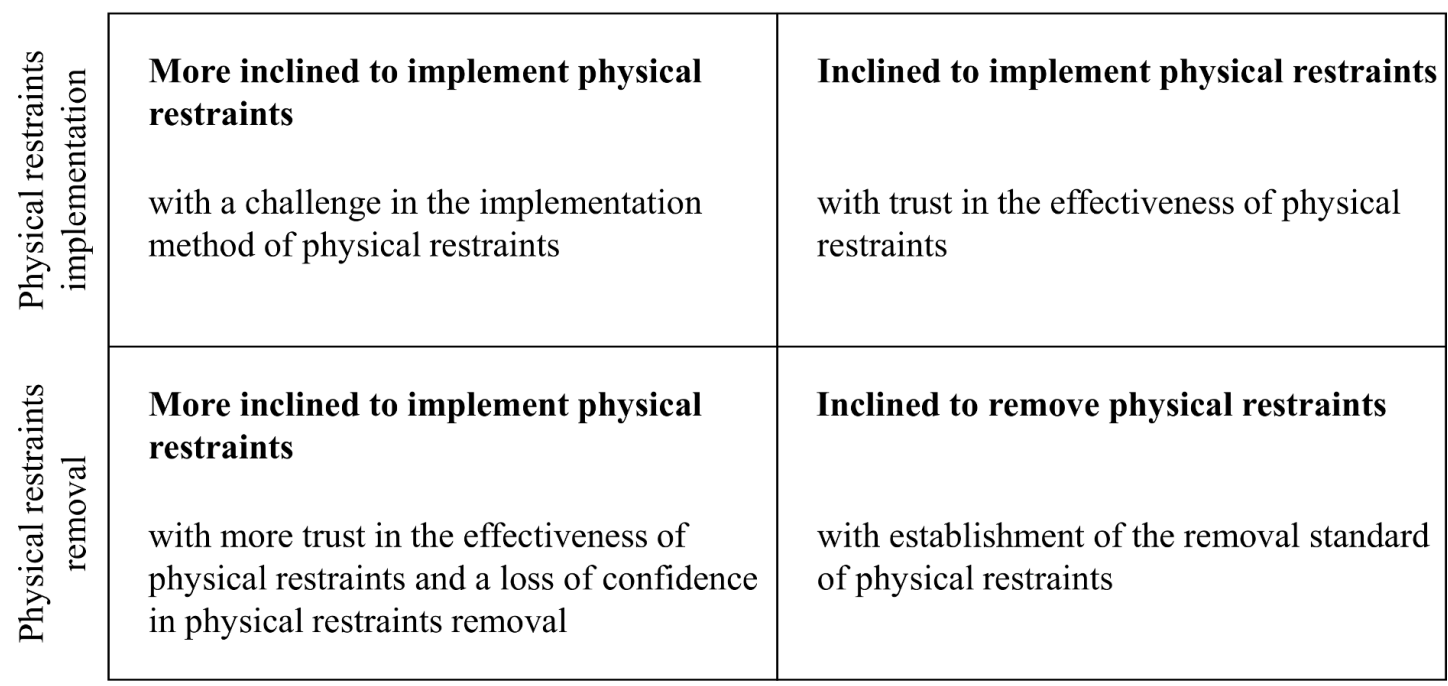

Figure 2 Nurses' inclination model for physical restraints implementation.

nurses' decisions to implement physical restraints were unchallenged. Nurse 8 reported:

It does not matter whether physical restraints are implemented. As long as you do not let patients have an unplanned extubation, intensivists do not care if you implement physical restraints.

\section{Subtheme: timely extubation by intensivists}

Critical care nurses stated that one condition for unplanned extubation was poor implementation of timely extubation by intensivists. Timely extubation meant that extubation was performed when patients met the extubation criteria. Patients with delayed extubation had a greater chance of unplanned extubation. Nurse 2 reported:

If the intensivists extubated in time, unplanned extubation would not occur in the patient.

\section{Subtheme: nurses' experiences with situations involving physical restraints and unplanned extubation}

Participants reported that decision-making also depended on nurses' experiences with physical restraints and unplanned extubation. Based on the four situations, a nurse inclination model for physical restraints implementation was constructed, as shown in figure 2. When nurses implemented physical restraints but unplanned extubation still occurred, nurses would not challenge the effectiveness of physical restraints for unplanned extubation but would challenge their implementation method of physical restraints; thus, they were more inclined to implement physical restraints. Nurse 5 reported:

If physical restraints are implemented and the patient still has an unplanned extubation, it must be that there is something wrong with the implementation method of physical restraints.
In the second situation, when nurses implemented physical restraints, unplanned extubation did not occur. Nurses believe that unplanned extubation did not occur because of physical restraints implementation, thereby trusting the effectiveness of physical restraints. Nurse 7 stated:

Precisely because I used physical restraints, unplanned extubation did not occur.

The third situation is when nurses removed physical restraints and unplanned extubation occurred, nurses will blame the reason for unplanned extubation on their removal of physical restraints and will place more trust in the effects of physical restraints. As nurse 2 put it:

I removed the physical restraints, and self-extubation occurred soon after. I never should have removed the physical restraints at that time.

In the last situation, when nurses removed physical restraints and unplanned extubation did not occur, they established a removal standard for physical restraints and were inclined to remove the physical restraints. Nurse 3 commented:

Maybe I will not use physical restraints if I manage a similar patient in the future.

\section{Subtheme: patients' possibility of unplanned extubation}

Participants described that patients could be divided into two types, high possibility of unplanned extubation and low possibility of unplanned extubation, according to different characteristics. Patients with a high possibility of unplanned extubation were more likely to be restrained; conversely, patients with a low possibility of unplanned extubation were less likely to be restrained (figure 3). The characteristics included patients' catheter types, patients' 

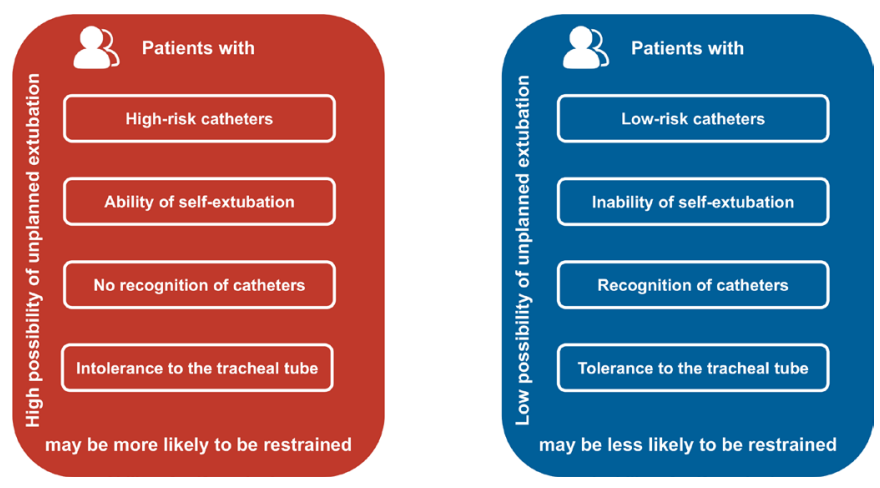

Figure 3 Patients' possibility of unplanned extubation.

self-extubation ability, patients' recognition of catheters and patients' tolerance of the tracheal tube.

Participants remarked that catheters used by critically ill patients were divided into high-risk and low-risk types. The tracheal tube is one of the most typical representatives of high-risk types. Patients with a tracheal tube were routinely restrained. Intensivist 3 said:

We prefer to order physical restraints for patients with catheters such as tracheal tubes.

The nasogastric tube is representative of the low-risk type. Patients with nasogastric tubes only will not be restrained. Nurse 1 stated:

If a patient just has a nasogastric tube, I do not usually use physical restraints.

Participants said that the patients' inability to move their upper limbs effectively means patients were unable to self-extubate. Even if patients had a tracheal tube, physical restraints were unnecessary. Patients without the ability to self-extubate usually had myasthenia gravis or hemiplegia or were in a deep coma. Nurse 9 indicated:

Patients with tracheal tubes who are unable to move their upper limbs do not need physical restraints, such as patients with hemiplegia, myasthenia gravis, or cervical spine fractures, because they have no unplanned extubation ability.

When patients could understand why they should not remove their tracheal tubes or other devices, the possibility of unplanned extubation was low. It was more challenging to obtain a good understanding of catheters in unplanned admission patients than in elective planned admission patients. Hence, clinicians were more inclined to implement physical restraints in unplanned admission patients. Nurse 8 described:

Unlike inpatients, unplanned admission patients have no chance to know these high-risk catheters. After waking up from anaesthesia, they may not even know where they are, so they want to pull out the tubes. Physical restraints need to be implemented on such patients.
Among catheters, the most intolerable catheter for patients was the tracheal tube. Even in patients with good recognition of catheters, self-extubation may occur. Patients' tolerance to endotracheal tubes is mainly reflected in whether patients will attempt to self-extubate when nurses implement sputum suction on patients. Nurse 10 explained:

There were patients with tracheal tubes who could read and write. Even if I implement sputum suction on them, they won't pull out the tube. I won't use physical restraints on them.

\section{DISCUSSION}

\section{A statement of the principal findings}

There were two principal findings in our study. First, the reason why critical care clinicians implemented physical restraints to prevent unplanned extubation was that the tense healthcare climate was caused by family members' rejection of mismatched expectations. As unplanned extubation was highly likely to create medical disputes, to avoid such disputes, the hospital placed excessive emphasis on unplanned extubation, which resulted in the lack of analysis of the cause of unplanned extubation and the implementation of strict measures for dealing with unplanned extubation. The tense healthcare climate also made it difficult to implement measures that may reduce the use of physical restraints, such as flexible visitation, in China. Second, the decision-making of physical restraints was affected by many factors: the shortage of nursing human resources, unsuitable ward environments, intensivists' attitudes towards physical restraints and unplanned extubation, timely extubation by intensivists', nurses' experiences with situations regarding physical restraints and unplanned extubation and patients' possibility of unplanned extubation. All of the above explained why physical restraints were commonly used in ICUs.

\section{Strengths and weaknesses of the study}

The main strength of this study lies in the use of a qualitative method to explore the root cause of physical restraints use from critical care clinicians' perspectives, including critical care nurses and intensivists. The sampling strategy was combined maximum variation sampling and criterion sampling. Thematic saturation occurred only when both trained researchers reached a consensus. However, this study is limited in several ways. First, all participants were from a general tertiary hospital in Hangzhou, China. Second, clinicians who chose to participate may have had more interest in physical restraints than clinicians who chose not to participate. Third, as the COVID-19 pandemic was ongoing during data collection, we did not explore the difference in critical care clinicians' clinical practice and clinical roles between the pre-COVID-19 pandemic and the COVID-19 pandemic, which might affect their decision-making about the use of physical restraints. Fourth, thematic saturation was based on 
interviews with additional critical care nurses instead of intensivists, which led to the number of intensivists who participated being less than the number of critical care nurses.

\section{Strengths and weaknesses in relation to other studies, discussing important differences in results}

The findings of this study showed that the avoidance of medical disputes might be one of the underlying reasons for physical restraints use. In our study, critical care clinicians expressed that the healthcare climate was tense in China, which increased the risk of medical disputes. Previous studies have demonstrated that medical disputes in China have surged over the past decade and their occurrence has remained high in recent years. ${ }^{34}$ The tense climate between clinicians and patients has led to verbal abuse, threats and even violence. ${ }^{35}$ One particular case of hospital violence, commonly known as Yinao in Chinese, describes organised unemployed gangs who are paid by patient families to create medical disturbances to obtain compensation for actual or perceived malpractice from hospitals. ${ }^{36}$ On 12 July 2018, a female doctor was stabbed by three gangsters in Tianjin and later died in the hospital. None of the three gangsters were patients of the doctor. ${ }^{37}$ This might be the reason why clinicians were afraid of medical disputes. Clinicians felt that family members' rejection of mismatched expectations was the reason behind the surge of medical disputes. However, this finding has not previously been described. Previous studies suggested that medical malpractice, patientphysician mistrust, information irregularity and high out-of-pocket expense might lead to medical disputes. ${ }^{38}$ In a tense medical climate, the occurrence of unplanned extubation would lead to medical disputes from clinicians' perspectives. Although we did not find evidence for the relationship between unplanned extubation and medical disputes, there were reports in the literature that indicated that unplanned extubation for ICU patients has drawn increasing attention because it can result in serious outcomes and even law issues between hospitals and family members. ${ }^{39}$ Our previous study found that nurses believed that physical restraints could efficiently prevent patients from having an unplanned extubation. ${ }^{25}$ In this study, critical care clinicians indicated that unplanned extubation was highly likely to cause medical disputes. Overall, physical restraints avoided medical disputes by preventing patients from having unplanned extubation. Avoiding medical disputes might be the reason why hospitals placed excessive emphasis on unplanned extubation in a measure that lacked the analysis of the cause of unplanned extubation and strictly dealt with the unplanned extubation act itself. However, imperfect hospital management led to the frequent use of physical restraints. These findings reflect those of Via-Clavero et al, ${ }^{40}$ who also found that leadership support and restraint policies in the ICU influenced the decision-making process of physical restraints. Moreover, flexible visitation could not be implemented in China because of the tense healthcare climate. A structured literature review found several challenges that hindered the broad application of open or flexible visitation in adult ICUs, such as negative staff perceptions and attitudes, patient protection, family and cultural consideration and organisational challenges. ${ }^{41} \mathrm{In}$ our study, clinicians agreed that flexible visitation might increase the workload and interrupt care, which was consistent with the review. However, the medical disputes that might be caused by flexible visitation were the reason for refusing to implement open visitation. Participants in our study expressed that the shortage of nursing human resources and unsuitable ward environments also influenced the implementation of physical restraints. These results are in accord with recent studies indicating that a better work environment overall and increased registered nurse hours per patient day were associated with lower restraint rates. ${ }^{42}$ This study also found that the characteristics of intensivists, nurses and patients influenced the use of physical restraints. Intensivists who supported or did not care about the use of physical restraints promoted physical restraints use. These results matched earlier studies that physicians do not consider physical restraints as an integral part of patients' medical management. ${ }^{43}$ Another influencing factor from intensivists was whether the patients were extubated in a timely manner. Nurses believed that unplanned extubation would not occur if intensivists extubated in a timely manner. Timely extubation needs to be balanced against the risk of a failed extubation, which carries a high risk of mortality, ${ }^{44}$ which might cause intensivists to delay extubation. Nevertheless, studies have proven that a strategy of delaying extubation was not associated with an increase in extubation success. ${ }^{45}$ In terms of nurses' experiences, we found that when nurses removed physical restraints and unplanned extubation did not occur, the removal standard of physical restraints was established. As in previous studies, nurses' experiences influenced the decision-making of physical restraints. ${ }^{46}$ Patients who were more likely to have unplanned extubation were more likely to be restrained from clinicians' perspectives. This also confirmed the results of previous studies that preventing the patient from removing a device, such as an endotracheal tube, was the most common reason for physical restraints use. ${ }^{6}$

\section{The meaning of the study: possible explanations and implications for clinicians and policy-makers}

These findings helped us to explain why critical care clinicians still implemented physical restraints in the ICU. Although critical care nurses have played a crucial role in the decision-making process regarding the use of physical restraints, it is time to adjust the direction of reducing the use of physical restraints. The prevention and resolution of medical disputes may be fundamental measures for reducing physical restraints because of the relationship between medical disputes and hospital violence. Policy-makers should pay more attention to the prevention and reduction of medical disputes. As crisis management of medical disputes can help hospitals change 
medical disputes from 'emergencies' to 'preoccurrence' events, grasp information in advance and change their thinking from 'post-emergency treatment' to 'preoccurrence control', ${ }^{47}$ it is necessary to establish a unified early warning standard and system for medical disputes. Hospital managers should shift the administration of unplanned extubation. The measures for dealing with unplanned extubation should be based on a comprehensive analysis of occurrence causes, which may change the status quo that nurses are responsible for all unplanned extubation. An increase in nursing human resources and a change in the ward environment are also important for changing physical restraints use. Education for clinicians can also be used to change the attitude of intensivists towards physical restraints and promote timely extubation; it may also influence the decision-making of nurses in the future. Physician-family communications need to be strengthened to change the irrational expectations of family members.

\section{Unanswered questions and future research}

Further research should be undertaken to investigate the precise relationship between unplanned extubation and medical disputes. It is also necessary to determine how the healthcare climate perceived by clinicians affects the use of physical restraints. Further work is required to carry out research on management bundles to promote the hospital management of unplanned extubation and physical restraints. An explicit decision support tool for physical restraints is needed for clinicians. The quantitative relationships between flexible visitation, nursing human resources, ward environment, intensivists' attitude, timely extubation and physical restraints use deserve to be studied in the future.

\section{Twitter Nianqi Cui @NianqiC}

Acknowledgements The authors wish to thank and acknowledge all clinicians who gave their time as participants and qualitative researcher Junhong Zhu, who reviewed the interview guide in this study. The authors would like to thank Wyatt William Gordon, who translated quotations, and Zhuming Bao, who reviewed the translated version of quotations.

Contributors NC and JJ conceived and designed the study. NC carried out the interviews and drafted the manuscript. NC and HR finished the initial transcription. $\mathrm{NC}$ and $\mathrm{RQ}$ analysed and interpreted the data. YZ, DC and $\mathrm{HZ}$ gave critical inputs to the intellectual content in the drafted manuscript. All authors read, revised and approved the final manuscript and take responsibility for the integrity of the work. $\mathrm{JJ}$ had full access to all of the data in the study and took responsibility for the integrity of the work.

Funding This work was supported by The Science Research Foundation of Chinese Nursing Association (grant number: ZHKY201913) and Zhejiang University Academic Award for Outstanding Doctoral Candidates (grant number: 202059). The funders had no role in the design and conduct of the study; collection, management, analysis and interpretation of the data; preparation, review or approval of the manuscript and decision to submit the manuscript for publication.

Competing interests None declared.

Patient consent for publication Not applicable.

Ethics approval Prior to undertaking the interview, ethical clearance was obtained from The Second Affiliated Hospital of Zhejiang University School of Medicine (2020131).

Provenance and peer review Not commissioned; externally peer reviewed.
Data availability statement № data are available.

Supplemental material This content has been supplied by the author(s). It has not been vetted by BMJ Publishing Group Limited (BMJ) and may not have been peer-reviewed. Any opinions or recommendations discussed are solely those of the author(s) and are not endorsed by BMJ. BMJ disclaims all liability and responsibility arising from any reliance placed on the content. Where the content includes any translated material, BMJ does not warrant the accuracy and reliability of the translations (including but not limited to local regulations, clinical guidelines, terminology, drug names and drug dosages), and is not responsible for any error and/or omissions arising from translation and adaptation or otherwise.

Open access This is an open access article distributed in accordance with the Creative Commons Attribution Non Commercial (CC BY-NC 4.0) license, which permits others to distribute, remix, adapt, build upon this work non-commercially, and license their derivative works on different terms, provided the original work is properly cited, appropriate credit is given, any changes made indicated, and the use is non-commercial. See: http://creativecommons.org/licenses/by-nc/4.0/.

\section{ORCID iD}

Nianqi Cui http://orcid.org/0000-0002-7963-4887

\section{REFERENCES}

1 Adhikari NKJ, Fowler RA, Bhagwanjee S, et al. Critical care and the global burden of critical illness in adults. Lancet 2010;376:1339-46.

2 Sauro KM, Soo A, Quan H, et al. Adverse events among hospitalized critically ill patients: a retrospective cohort study. Med Care 2020;58:38-44

3 Chen C-Z, Chu Y-C, Lee C-H, et al. Factors predicting reintubation after unplanned extubation. J Formos Med Assoc 2002;101:542-6.

4 Kapadia FN, Bajan KB, Raje KV. Airway accidents in intubated intensive care unit patients: an epidemiological study. Crit Care Med 2000;28:659-64.

5 Kiekkas P, Aretha D, Panteli E, et al. Unplanned extubation in critically ill adults: clinical review. Nurs Crit Care 2013;18:123-34.

6 Crutchfield P, Gibb TS, Redinger MJ, et al. The Conditions for Ethical Application of Restraints. Chest 2019;155:617-25.

7 Bleijlevens MHC, Wagner LM, Capezuti E, et al. Physical restraints: consensus of a research definition using a modified Delphi technique. J Am Geriatr Soc 2016;64:2307-10.

8 Devlin JW, Skrobik Y, Gélinas C, et al. Clinical practice guidelines for the prevention and management of pain, Agitation/Sedation, delirium, immobility, and sleep disruption in adult patients in the ICU. Crit Care Med 2018;46:e825-73.

9 Ertuğrul B, Özden D. The effect of physical restraint on neurovascular complications in intensive care units. Aust Crit Care 2020;33:30-8.

10 Mehta S, Cook D, Devlin JW, et al. Prevalence, risk factors, and outcomes of delirium in mechanically ventilated adults. Crit Care Med 2015;43:557-66.

11 Lach HW, Leach KM. Changing the practice of physical restraint use in acute care. The University of lowa College of nursing Barbara and Richard Csomay center for Gerontological excellence, lowa City, la 2014.

12 Registered nurses' association of Ontario. promoting safety: alternative approaches to the use of restraints, 2012. Available: http://rnao.ca/bpg/guidelines/promoting-safety-alternativeapproaches-use-restraints [Accessed 18 Jun 2021].

13 Zhang C, Liu D, He Q. The characteristics of ICU physical restraint use and related influencing factors in China: a multi-center study. Ann Palliat Med 2021;10:1198-206.

14 Suliman M. Prevalence of physical restraint among ventilated intensive care unit patients. J Clin Nurs 2018;27:3490-6.

15 Lawson TN, Tan A, Thrane SE, et al. Predictors of new-onset physical restraint use in critically ill adults. Am J Crit Care 2020;29:92-102.

16 Maiden MJ, Bone A, Fitzpatrick M, et al. Physical restraint of patients in Australia and New Zealand intensive care units. Intensive Care Med 2021;47:234-6.

17 Burry L, Rose L, Ricou B. Physical restraint: time to let go. Intensive Care Med 2018;44:1296-8.

18 Sandhu SK, Mion LC, Khan RH, et al. Likelihood of ordering physical restraints: influence of physician characteristics. J Am Geriatr Soc 2010;58:1272-8.

19 Langley G, Schmollgruber S, Egan A. Restraints in intensive care units--a mixed method study. Intensive Crit Care Nurs 2011;27:67-75

20 Perez D, Peters K, Wilkes L, et al. Physical restraints in intensive care-An integrative review. Aust Crit Care 2019;32:165-74. 
21 Goethals S, Dierckx de Casterlé B, Gastmans C. Nurses' decisionmaking in cases of physical restraint: a synthesis of qualitative evidence. J Adv Nurs 2012;68:1198-210.

22 Lei R, Jiang X, Liu Q, et al. Nurse education to reduce physical restraints use in ICU: a scoping review. Nurs Crit Care 2020. doi:10.1111/nicc.12557. [Epub ahead of print: 23 Sep 2020].

23 Möhler R, Richter T, Köpke S, et al. Interventions for preventing and reducing the use of physical restraints in long-term geriatric care. Cochrane Database Syst Rev 2011;2:CD007546.

24 Karagozoglu S, Ozden D, Yildiz FT, Knowledge YFT. Knowledge, attitudes, and practices of Turkish intern nurses regarding physical restraints. Clin Nurse Spec 2013;27:262-71.

25 Cui N, Qiu R, Zhang Y, et al. "Patient Comfort Can Be Sacrificed for Patient Safety" - Perception and Practice Reported by Critical Care Nurses Toward Physical Restraints: A Qualitative Descriptive Study. Front Med 2021;8.

26 Bradshaw C, Atkinson S, Doody O. Employing a qualitative description approach in health care research. Glob Qual Nurs Res 2017;4:233339361774228.

27 Patton MQ. Qualitative research and evaluation methods: integrating theory and practice: thousand oaks. CA: Sage, 2015.

28 Sullivan-Bolyai S, Bova C, Harper D. Developing and refining interventions in persons with health disparities: the use of qualitative description. Nurs Outlook 2005;53:127-33.

29 O'Brien BC, Harris IB, Beckman TJ, et al. Standards for reporting qualitative research: a synthesis of recommendations. Acad Med 2014;89:1245-51.

30 Cui N, Wang R, Song F, et al. Experiences and perceptions of male nursing students in a single-sex class: a qualitative descriptive study. Nurse Educ Pract 2021;51:102996.

31 Wang $\mathrm{R}$, Cui N, Long $\mathrm{M}$, et al. Barriers to uptake of hepatitis $\mathrm{C}$ virus (HCV) health intervention among men who have sex with men in Southwest China: a qualitative study. Health Soc Care Community 2021;29:445-52.

32 Chen D, Song F, Cui N, et al. The perceptions and views of rural residents towards COVID-19 recovered patients in China: a descriptive qualitative study. Int J Gen Med 2021;14:709-20.

33 Braun V, Clarke V. Using thematic analysis in psychology. Qual Res Psychol 2006;3:77-101.

34 Lan T, Pan J. The association of market mix of hospital ownership with medical disputes: evidence from China. Inquiry 2020;57:46958020971403.
35 Tucker JD, Cheng Y, Wong B, et al. Patient-physician mistrust and violence against physicians in Guangdong Province, China: a qualitative study. BMJ Open 2015;5:e008221.

36 Hesketh T, Wu D, Mao L, et al. Violence against doctors in China. BMJ 2012;345:e5730.

37 Guanchazhe. Tianjin procuratorate Approved the arrest of criminal suspects of hospital violence of the armed police Froce Hospital, 2018. Available: https://www.guancha.cn/society/2018_07_17 464513.shtml [Accessed 18 Jun 2021]

38 Lyu S-Y, Liao C-K, Chang K-P, et al. Analysis of medical litigation among patients with medical disputes in cosmetic surgery in Taiwan. Aesthetic Plast Surg 2011;35:764-72.

39 Ai Z-P, Gao X-L, Zhao X-L. Factors associated with unplanned extubation in the intensive care unit for adult patients: a systematic review and meta-analysis. Intensive Crit Care Nurs 2018;47:62-8.

40 Via-Clavero G, Sanjuán-Naváis M, Romero-García M, et al. Eliciting critical care nurses' beliefs regarding physical restraint use. Nurs Ethics 2019;26:1458-72.

41 Ning J, Cope V. Open visiting in adult intensive care units - A structured literature review. Intensive Crit Care Nurs 2020;56:102763.

42 Olds D, Cramer E. Predictors of physical restraint use on critical care units: an observational structural equation modeling approach. Int $J$ Nurs Stud 2021;118:103925.

43 De Jonghe B, Constantin J-M, Chanques G, et al. Physical restraint in mechanically ventilated ICU patients: a survey of French practice. Intensive Care Med 2013;39:31-7.

44 Coplin WM, Pierson DJ, Cooley KD, et al. Implications of extubation delay in brain-injured patients meeting standard weaning criteria. Am $J$ Respir Crit Care Med 2000;161:1530-6.

45 McCredie VA, Ferguson ND, Pinto RL, et al. Airway management strategies for brain-injured patients meeting standard criteria to consider extubation. A prospective cohort study. Ann Am Thorac Soc 2017;14:85-93.

46 Stinson KJ. Nurses' attitudes, clinical experience, and practice issues with use of physical restraints in critical care units. Am J Crit Care 2016;25:21-6.

47 Yin T, Liu Z, Xu Y. Analysis of crisis management of medical disputes in China and Australia: a narrative review article. Iran J Public Health 2019;48:2116-23. 